\title{
Preemptive use of gabapentin significantly decreases postoperative pain and rescue analgesic requirements in laparoscopic cholecystectomy
}

\author{
[L'usage préventif de gabapentine diminue significativement la douleur postopératoire \\ et les besoins d'analgésique de secours lors d'une cholécystectomie laparoscopique]
}

Chandra Kant Pandey MD, Shio Priye MBBs, Surendra Singh MD, Uttam Singh PhD, Ram Badan Singh MD PDCC, Prabhat Kumar Singh MD

Purpose: To evaluate the comparative preemptive effects of gabapentin and tramadol on postoperative pain and fentanyl requirement in laparoscopic cholecystectomy.

Methods: Four hundred fifty-nine ASA I and II patients were randomly assigned to receive $300 \mathrm{mg}$ gabapentin, $100 \mathrm{mg}$ tramadol or placebo in a double-blind manner two hours before laparoscopic cholecystectomy under general anesthesia. Postoperatively, patients' pain scores were recorded on a visual analogue scale every two hours for the initial $12 \mathrm{hr}$ and thereafter every three hours for the next $12 \mathrm{hr}$. Patients received fentanyl $2 \mu \mathrm{g} \cdot \mathrm{kg}^{-1}$ intravenously on demand. The total fentanyl consumption for each patient was recorded.

Results: Patients in the gabapentin group had significantly lower pain scores at all time intervals $(2.65 \pm 3.00,1.99 \pm 1.48,1.40 \pm$ $0.95,0.65 \pm 0.61)$ in comparison to tramadol $(2.97 \pm 2.35,2.37$ $\pm 1.45,1.89 \pm 1.16,0.87 \pm 0.50)$ and placebo $(5.53 \pm 2.22$, $3.33 \pm 1.37,2.41 \pm 1.19,1.19 \pm 0.56)$. Significantly less fentanyl was consumed in the gabapentin group $(221.16 \pm 52.39 \mu \mathrm{g})$ than in the tramadol $(269.60 \pm 44.17 \mu \mathrm{g})$ and placebo groups (355.86 $\pm 42.04 \mu \mathrm{g} ; P<0.05)$. Sedation (33.98\%), nausea/retching/vomiting $(24.8 \%)$ were the commonest side effects in the gabapentin group whereas respiratory depression (3.9\%) was the commonest in the tramadol group and vertigo (7.8\%) in the placebo group.

Conclusion: Preemptive use of gabapentin significantly decreases postoperative pain and rescue analgesic requirement in laparoscopic cholecystectomy.
Objectif: Évaluer et comparer les effets préventifs de la gabapentine et du tramadol sur la douleur postopératoire et les besoins de fentanyl lors d'une cholécystectomie laparoscopique.

Méthode : Quatre cent cinquante-neuf patients d'état physique ASA I et II ont été répartis au hasard et ont reçu 300 mg de gabapentine, 100 mg de tramadol ou un placebo, en double aveugle, deux heures avant la cholécystectomie laparoscopique sous anesthésie générale. Après l'opération, les scores de douleur ont été notés sur l'échelle visuelle analogique toutes les deux heures pendant les 12 premières heures et toutes les trois heures pendant les $12 \mathrm{~h}$ suivantes. Les patients ont reçu $2 \mu \mathrm{g} \cdot \mathrm{kg}^{-1}$ de fentanyl intraveineux sur demande et la consommation totale a été notée pour chacun.

Résultats : Les patients du groupe gabapentine ont présenté des scores de douleur significativement plus bas pour tous les intervalles de mesures (2,65 $\pm 3,00 ; 1,99 \pm 1,48 ; 1,40 \pm 0,95 ; 0,65 \pm 0,61)$ que ceux du groupe tramadol $(2,97 \pm 2,35 ; 2,37 \pm 1,45 ; 1,89 \pm$ I, I6; 0,87 $\pm 0,50)$ ou placebo $(5,53 \pm 2,22 ; 3,33 \pm 1,37 ; 2,41$ $\pm 1,19 ; 1,19 \pm 0,56)$. La demande de fentanyl a été significativement plus basse avec la gabapentine (221, $16 \pm 52,39 \mu \mathrm{g})$ qu'avec le tramadol $(269,60 \pm 44,17 \mu \mathrm{g})$ ou le placebo $(355,86 \pm 42,04$ $\mu$ g; $P<0,05)$. La sédation (33,98\%), les nausées/haut-lecœur/vomissements (24,8\%) ont été les effets négatifs les plus fréquents avec la gabapentine tandis que la dépression respiratoire (3,9\%) a été plus fréquente avec le tramadol et le vertige (7,8\%) avec le placebo.

Conclusion : L'usage préventif de gabapentine diminue significativement la douleur postopératoire et la demande d'analgésique de secours lors de la cholécystectomie laparoscopique.

From the Department of Anaesthesiology and Biostatistics, Sanjay Gandhi Postgraduate Institute of Medical Sciences, Lucknow, India. Address correspondence to: Dr. Chandra Kant Pandey, Department of Anaesthesiology, Sanjay Gandhi Postgraduate Institute of Medical Sciences, Lucknow 226014, India. Phone: 0091-522-2668800, ext. 2490; Fax: 0091-522-2668017 (attention to Dr. C.K. Pandey); E-mail: ckpandey@sgpgi.ac.in Accepted for publication September 16, 2003.

Revision accepted January 14, 2004. 
$\mathrm{P}$

ERIPHERAL tissue injury provokes peripheral sensitization (a reduction in the threshold of nociceptor afferent peripheral terminals) and central sensitization (an activity dependent increase in the excitability of spinal neurons).$^{1,2}$ These changes contribute to the postinjury pain hypersensitivity state which manifests as an increase in the responsiveness to noxious stimuli and a decrease in the pain threshold, both at the site of injury and in the surrounding uninjured tissue. ${ }^{1,2}$ The optimal form of treatment is that applied pre, intra and postoperatively to preempt the establishment of pain hypersensitivity during and after surgery. The preemptive treatment could be directed at the periphery, at inputs along sensory axons, and at central neurons. Different treatment regimens could be used at different times relative to surgery to maximize the prevention of pain in response to different levels of sensory inputs. ${ }^{1,2}$

Gabapentin and tramadol both have demonstrated analgesic effects in clinical trials as a preemptive analgesic and in acute postoperative pain management; however experience with gabapentin is limited. ${ }^{3-6} \mathrm{We}$ investigated whether preemptive use of gabapentin 300 $\mathrm{mg}$ and tramadol $100 \mathrm{mg}$ orally could reduce postoperative pain and fentanyl consumption in the initial 24 hr after laparoscopic cholecystectomy. We used a small dose of gabapentin $(300 \mathrm{mg}$ ) as its bioavailability is $60 \%$ and decreases with increasing doses.

\section{Methods}

The Institute's Ethics Committee approved this study and written informed consent was obtained from each participant. On the assumption that a $20 \%$ decrease in postoperative fentanyl consumption required 153 patients in each group for $80 \%$ power with an $\alpha=$ 0.05 , we recruited 459 patients ASA physical status I and II of both sexes scheduled for elective laparoscopic cholecystectomy. Exclusion criteria were: body weight exceeding $20 \%$ of the ideal body weight; age older than $70 \mathrm{yr}$ or younger than $18 \mathrm{yr}$; known history of hypersensitivity to any drug; history of drug or alcohol abuse; uncontrolled concomitant medical diseases (hypertension, bronchial asthma, diabetes mellitus); patients with history of chronic pain conditions; impaired kidney or liver function; cholelithiasis with known common bile duct pathology or indications of cholecystectomy other than cholelithiasis, laparoscopic cholecystectomy converted into open cholecystectomy; and the administration of analgesics within 48 hr of scheduled surgery.

All patients received oral lorazepam $0.04 \mathrm{mg} \cdot \mathrm{kg}^{-1}$ the evening before surgery and on the morning of surgery.
Patients were randomly assigned to receive oral $300 \mathrm{mg}$ gabapentin, $100 \mathrm{mg}$ tramadol or a matching placebo two hours before surgery with the help of a computer generated table of random numbers. Anesthesia was induced with propofol $2 \mathrm{mg} \cdot \mathrm{kg}^{-1}$, fentanyl $2 \mu \mathrm{g} \cdot \mathrm{kg}^{-1}$, vecuronium bromide $800 \mu \mathrm{gg} \cdot \mathrm{kg}^{-1}$ and lidocaine 1.5 $\mathrm{mg} \cdot \mathrm{kg}^{-1}$ one minute before intubation. Anesthesia was maintained with a propofol infusion 100 to 200 $\mu \mathrm{g} \cdot \mathrm{kg}^{-1} \cdot \mathrm{min}^{-1}$ and $70 \%$ nitrous oxide in oxygen and intermittent vecuronium when indicated. After completion of surgery, neuromuscular blockade was reversed with atropine $0.02 \mathrm{mg} \cdot \mathrm{kg}^{-1}$ and neostigmine 0.04 $\mathrm{mg} \cdot \mathrm{kg}^{-1}$ and patients were extubated when adequate spontaneous ventilation was established. After surgery a senior resident, who was not part of the anesthesia team, recorded the pain score at rest on a visual analogue scale (VAS; $0-10 \mathrm{~cm} ; 0=$ no pain and $10=$ worst possible pain) every two hours for the initial $12 \mathrm{hr}$ and then every three hours for the next $12 \mathrm{hr}$. From these data, the maximum pain scores at different time intervals $(0-6$, 6-12, 12-18 and 18-24 hr) for each patient were considered for statistical analysis. $2 \mu \mathrm{g} \cdot \mathrm{kg}^{-1}$ fentanyl was administered intravenously by a staff nurse as a rescue analgesic at the patient's demand. The total rescue fentanyl requirement in $24 \mathrm{hr}$ by each patient was recorded. The Ramsay sedation scale ( 1 , anxious, agitated or restless; 2, cooperative, oriented, and tranquil; 3, responds to command; 4 , asleep but has a brisk response to light glabellar tap or loud auditory stimulus; 5 , asleep, has a sluggish response to a light glabellar tap or loud auditory stimulus; 6 , asleep, no response) was used to record the sedation score. ${ }^{7}$ Side effects including nausea/retching/vomiting, respiratory depression (respiratory rate $<8$ breaths $\cdot \mathrm{min}^{-1}$ or oxygen saturation $<90 \%$ without oxygen supplementation), vertigo, ataxia, somnolence, visual disturbance, lightheadedness and headache were recorded. If indicated, side effects were treated as required (oxygen saturation $<90 \%$, two or greater than two episodes of vomiting, Ramsay sedation score 5 or more).

TABLE I Demographic variables

\begin{tabular}{llllc}
\hline & Age $(y r)$ & Weight $(\mathrm{kg})$ & \multicolumn{2}{c}{ Sex } \\
& & & male & female \\
\hline $\begin{array}{l}\text { Gabapentin group } \\
(n=153)\end{array}$ & $41.65 \pm 11.19$ & $58.76 \pm 7.80$ & 54 & 99 \\
$\begin{array}{l}\text { Tramadol group } \\
(n=153)\end{array}$ & $40.03 \pm 10.84$ & $58.69 \pm 8.15$ & 45 & 108 \\
$\begin{array}{l}\text { Placebo group } \\
(n=153)\end{array}$ & $43.49 \pm 11.14$ & $57.72 \pm 7.81$ & 52 & 101 \\
\hline
\end{tabular}


TABLE II Visual analogue scale (VAS) scores in different time intervals and total fentanyl consumption (mean \pm SD)

\begin{tabular}{|c|c|c|c|c|c|}
\hline & $0-6 \mathrm{hr}$ & $6-12 \mathrm{hr}$ & $12-18 \mathrm{hr}$ & $18-24 \mathrm{hr}$ & Fentanyl consumed $(\mu g)$ \\
\hline Gabapentin group & $2.65 \pm 3.00^{*}$ & $1.99 \pm 1.48^{*}$ & $1.40 \pm 0.95^{*}$ & $0.65 \pm 0.61 *$ & $221.16 \pm 52.39 *$ \\
\hline Tramadol group & $2.97 \pm 2.35$ & $2.37 \pm 1.45 \dagger$ & $1.89 \pm 1.16 \dagger$ & $0.87 \pm 0.50 \dagger$ & $269.60 \pm 44.17 \dagger$ \\
\hline Placebo group & $5.53 \pm 2.22 \ddagger$ & $3.33 \pm 1.37 \ddagger$ & $2.41 \pm 1.19 \ddagger$ & $1.19 \pm 0.56 \ddagger$ & $355.86 \pm 42.04 \ddagger$ \\
\hline
\end{tabular}

${ }^{\star} P$ value $<0.05$ (gabapentin vs placebo); $\dagger P$ value $<0.05$ (gabapentin $v s$ tramadol); $\ddagger P$ value $<0.05$ (tramadol $v s$ placebo)

TABLE III Side effects observed in the three study groups

\begin{tabular}{llll}
\hline & Sedation & Nausea/retching/vomiting & Respiratory depression \\
\hline Gabapentin & $52(33.98 \%)$ & $38(24.8 \%)$ & $0 \dagger$ \\
Tramadol & $44(28.8 \%)^{* *}$ & $26(17.6 \%)^{* *}$ & $6(3.9 \%)^{* *}$ \\
Placebo & $5(3.3 \%)^{*}$ & $8(5.2 \%)^{*}$ & $1.3 \%)$ \\
\hline
\end{tabular}

${ }^{\star} P$ value $<0.05$ (gabapentin $v s$ placebo); ${ }^{*} P$ value $<0.05$ (tramadol $v s$ placebo); $\dagger P$ value $<0.05$ (gabapentin $v s$ tramadol)

After completion of the study, the data were unblinded and entered into the statistical software package SPSS 9. The mean and standard deviation (SD) of pain score for all three groups at time intervals of zero to six, six to 12,12 to 18 and 18 to $24 \mathrm{hr}$ were calculated and were analyzed with two-factor ANOVA for repeated measures. Similarly, total fentanyl consumption in each group was compared with unpaired t tests. The Chi-square test was applied to test the association between side effects and the study groups and test of proportion ' $\mathrm{Z}$ test' was used to test the significance of side effects among the groups. A value of $P<0.05$ was considered statistically significant.

\section{Results}

There were no demographic differences among the three groups (Table I). In comparison with placebo and tramadol, patients in the gabapentin group had significantly lower VAS scores in all time intervals (except $0-6 \mathrm{hr}$ in the tramadol group) during the study period and required significantly less fentanyl for postoperative pain management (Figure 2). Patients in the tramadol group had significantly lower VAS scores than patients in the placebo group in all time intervals and required significantly less rescue analgesic for postoperative pain management (Table II; $P<0.05$ ). In the placebo group, VAS scores at time intervals 12 to $18 \mathrm{hr}$ and 18 to $24 \mathrm{hr}$ were significantly higher in females $(2.56 \pm 1.20$ and $1.27 \pm 0.56)$ than in males $(2.12 \pm 1.11$ and $1.04 \pm 0.52)$. Male patients in the gabapentin group required significantly less fentanyl than female patients $(188.88 \pm 44.16 \mu \mathrm{g}$ vs $239.40 \pm$ $54.55 \mu \mathrm{g} ; 2.94 \pm 0.68 \mu \mathrm{g} \cdot \mathrm{kg}^{-1}$ ps $\left.4.36 \pm 1.02 \mu \mathrm{g} \cdot \mathrm{kg}^{-1}\right)$. There was no significant difference in fentanyl consumption in the tramadol and placebo groups

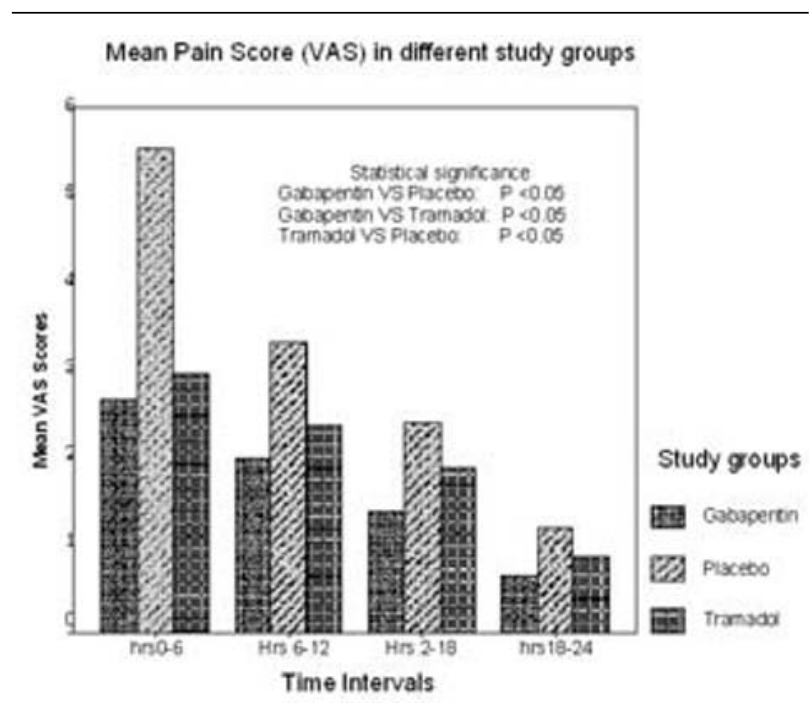

FIGURE 1 Mean pain score on visual analogue scale (VAS) in gabapentin, placebo, and tramadol groups at different time intervals.

between male and female patients. A higher incidence of sedation (33.98\%), nausea/retching/vomiting $(24.8 \%)$ was found in the gabapentin group whereas a higher incidence of respiratory depression $(3.9 \%)$ was present in the tramadol group and vertigo $(7.8 \%)$ in the placebo group (Table III). No patient in any group reported somnolence, ataxia, lightheadedness, dizziness, headache and visual disturbances. 


\section{Mean Fentanyl dose consumed in different study groups}

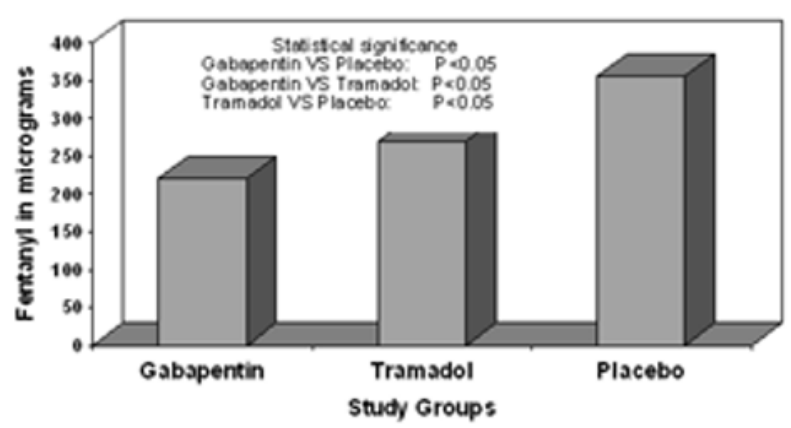

FIGURE 2 Mean dose of rescue analgesic fentanyl consumption in gabapentin, tramadol and placebo groups.

\section{Discussion}

The present study has demonstrated the significant analgesic effect of the preemptive use of $300 \mathrm{mg}$ oral gabapentin over $100 \mathrm{mg}$ tramadol and placebo after laparoscopic cholecystectomy. A decrease in total analgesic consumption along with a significant decrease in VAS pain scores was found in patients who received gabapentin two hours before surgery in comparison to patients who received placebo (Table II; Figure 1). The VAS score in the gabapentin group was significantly less in comparison to tramadol except at the zero to six hour interval $(2.65 \pm 3.00$ vs $2.97 \pm 2.35)$, suggests that the preoperative administration of gabapentin has a more prolonged analgesic effect than tramadol (Table II; Figure 1). There was a higher incidence of side effects in patients who received gabapentin but none of the patients required treatment and the side effects were well tolerated. Six patients who received tramadol developed respiratory depression and required supplementation with oxygen to maintain saturation $>90 \%$. Patients who received placebo had a higher incidence of vertigo but did not require clinical intervention (Table III).

Gabapentin is an antiepileptic drug and a structural analogue of gamma amino butyric acid (GABA). ${ }^{8}$ Gabapentin does not bind with plasma protein and is not metabolized in humans. After a single oral dose of $300 \mathrm{mg}$, mean maximum plasma concentrations are attained in two to three hours. Absorption kinetics of gabapentin are dose dependent, possibly due to a saturable transport system. ${ }^{8}$ The bioavailability of a single $300 \mathrm{mg}$ oral dose of gabapentin is $60 \%$ and decreases with an increasing dose. Elimination of gabapentin is by renal clearance and the elimination half-life is about five to seven hours after a single oral dose of 200 to $400 \mathrm{mg}$. Despite its structural similarity to GABA, it does not act via mechanisms related to GABA. ${ }^{8}$ Though the exact mechanism of action of gabapentin is not known, proposed mechanisms are its ability to: increase the concentration and the rate of synthesis of GABA in the brain; bind with high affinity to binding sites in brain tissues that are associated with an auxiliary subunit of voltage sensitive calcium channels $\left(\alpha_{2} \delta\right.$ subunits $)$; reduce the release of monoamine neurotransmitters; inhibit voltage activated sodium channels; and increase serotonin concentrations in human blood..$^{9,10}$

Tramadol is a centrally acting opioid analgesic with an analgesic potency equivalent to pethidine. ${ }^{11}$ It also modifies transmission of pain impulses by inhibition of monoamine re-uptake. ${ }^{10}$ After oral administration, tramadol appears in plasma within 15 to $45 \mathrm{~min}$, reaching a peak plasma concentration at a mean of two hours. The bioavailability of tramadol after a single oral dose is approximately $68 \%$ and increases to 90-100\% on multiple administrations; it undergoes hepatic metabolism and renal excretion. ${ }^{11}$ The mean elimination half-life is five to six hours and elimination half-life may increase approximately twofold in patients with impaired hepatic and renal functions. ${ }^{11}$

We used $300 \mathrm{mg}$ of gabapentin and $100 \mathrm{mg}$ of tramadol orally because both drugs have similar pharmacokinetic properties, as described above. Both drugs, in earlier clinical trials, have been used as a preemptive analgesic and found to be safe and effective. ${ }^{3-5,12,13}$ The preemptive administration of gabapentin and tramadol approximately two hours before surgery appears rational in order to attain maximal plasma concentrations at the time of surgical stimuli. It has also been demonstrated that a single dose of $600 \mathrm{mg}$ of gabapentin added to $60 \mathrm{mg}$ slow release morphine increases pain tolerance to the cold pressure test in humans. Though the cold pressure test is a test of short duration and tolerance to pain and is not synonymous with analgesic efficacy, the available data are useful when planning the treatment of acute pain with gabapentin. ${ }^{13}$ It was also demonstrated that a $600 \mathrm{mg}$ single dose of gabapentin enhanced the effect of morphine but side effects appeared in approximately $40 \%$ of volunteers when these drugs were used concomitantly. ${ }^{13}$ Another study of 22 human volunteers who received $1200 \mathrm{mg}$ of gabapentin or placebo in a double-blind, randomized cross-over fashion on two separate study days, demonstrated reduced primary mechanical allodynia in acute inflammation following a first degree thermal injury, suggesting that 
gabapentin had clinical potential in the treatment of postoperative pain. ${ }^{14}$ The analgesic efficacy of gabapentin when it was used as a preemptive analgesic (one hour before the surgical stimulus) has been demonstrated in surgical patients by Dirks et al. who found a substantial reduction in postoperative morphine consumption without significant side effects. ${ }^{12}$ This lower incidence of side effects despite a larger dose may be explained by the fact that patients were assessed in the immediate postoperative period, from zero to four hours after surgery, and anesthetics may have masked the side effects of gabapentin. In our study, we followed all patients for $24 \mathrm{hr}$ after surgery. There was an increased incidence of sedation, nausea/retching/vomiting in the gabapentin group in comparison to placebo but side effects were comparable in patients who received tramadol (Table III).

It is suggested that central sensitization plays an important role not only in chronic pain states, but also in postoperative pain. ${ }^{12}$ The relative contribution of various pain mechanisms to postoperative pain has not been established. ${ }^{10}$ Numerous antihyperalgesic methods and drugs have been evaluated in order to reduce the central neuronal hyperexcitability which, theoretically, may amplify postoperative pain. ${ }^{12}$ Although gabapentin has been used in the treatment of neuropathic pain syndromes, it has also demonstrated potent antihyperalgesic proprieties in preclinical and clinical studies, without affecting acute nocicep-

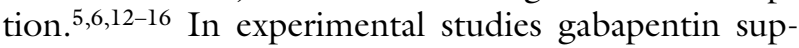
pressed experimentally induced hyperalgesia and its intrathecal administration reduced tactile allodynia after incision. Gabapentin enhanced pain behaviour in rats after formalin-induced pain and reduced mechanical hyperalgesia in a rat model of postoperative pain. ${ }^{17,18}$ In a clinical study, gabapentin demonstrated substantial inhibitory effects not only on the development but also on established secondary allodynia and hyperalgesia resulting from sensitization of the skin with heat and capsaicin in volunteers. ${ }^{19}$ The magnitude of this effect was comparable to the effect observed with the potent opioid remifentanil but, in contrast, without affecting acute nociceptive threshold and with only moderate side effects. ${ }^{20}$

In summary, the exact mechanism of action of gabapentin is not well understood but clinical and experimental studies have demonstrated its analgesic efficacy and safety in physiological as well as in pathological pain. Our clinical study also demonstrated that a 300-mg single preemptive oral dose of gabapentin significantly decreases the incidence of pain until $24 \mathrm{hr}$ postoperatively and decreases total fentanyl consumption in comparison to a $100-\mathrm{mg}$ single oral dose of tramadol and placebo in laparoscopic cholecystectomy. The side effects were tolerated by the patients and were comparable to those of tramadol.

\section{References}

$1 W u C T, \Upsilon u J C$, Yeh CC, et al. Preincisional dextromethorphan treatment decreases postoperative pain and opioid requirement after laparoscopic cholecystectomy. Anesth Analg 1999; 88: 1331-4.

2 Woolf CJ, Chong MS. Preemptive analgesia-treating postoperative pain by preventing the establishment of central sensitization. Anesth Analg 1993; 77: 362-79.

3 Chiaretti A, Viola L, Pietrini D, et al. Preemptive analgesia with tramadol and fentanyl in pediatric neurosurgery. Childs Nerv Syst 2000; 16: 93-9.

4 Naguib M, Seraj M, Attia M, Samarkandi AH, Seet $M$, Jaroudi $R$. Perioperative antinociceptive effects of tramadol. A prospective, randomized, double-blind comparison with morphine. Can J Anaesth 1998; 45: 1168-75.

5 Fassoulaki A, Patris K, Sarantopoulos C, Hogan Q. The analgesic effect of gabapentin and mexilentine after breast surgery for cancer. Anesth Analg 2002; 95 : 985-91.

6 Pandey CK, Bose N, Garg G, et al. Gabapentin for the treatment of pain in Guillain-Barré syndrome: a double-blinded, placebo-controlled, crossover study. Anesth Analg 2002; 95: 1719-23.

7 Ramsay MA, Savege TM, Simpson BR, Goodwin R. Controlled sedation with alphaxalone-alphadolone. BMJ 1974; 2: 656-9.

8 Goa KL, Sorkin EM. Gabapentin. A review of its pharmacological properties and clinical potential in epilepsy. Drugs 1993; 46: 409-27.

9 Taylor CP, Gee NS, Su TZ, et al. A summary of mechanistic hypotheses of gabapentin pharmacology. Epilepsy Res 1998; 29: 233-49.

10 Gee NS, Brown JP, Dissanayake VU, Offord J, Thurlow $R$, Woodruff GN. The novel anticonvulsant drug, gabapentin (neurontin), binds to the $\alpha_{2} \delta$ subunit of a calcium channel. J Biol Chem 1996; 271: 5768-76.

11 Lee CR, McTavish D, Sorkin EM. Tramadol. A preliminary review of its pharmacodynamic and pharmacokinetic properties, and therapeutic potential in acute and chronic pain states. Drugs 1993; 46: 313-40.

12 Dirks J, Fredensborg BB, Christensen D, Fomsgaard JS, Flyger H, Dahl JB. A randomized study of the effects of single-dose gabapentin versus placebo on postoperative pain and morphine consumption after mastectomy. Anesthesiology 2002; 97: 560-4.

13 Eckhardt K, Ammon S, Hofmann U, Riebe A, Gugeler $N$, Mikus $G$. Gabapentin enhances the analgesic effect of morphine in healthy volunteers. Anesth Analg 2000; 
91: 185-91.

14 Werner MU, Perkins FM, Holte K, Pedersen JL, Keblet $H$. Effects of gabapentin in acute inflammatory pain in humans. Reg Anesth Pain Med 2001; 26: 322-8.

15 Mao J, Chen LL. Gabapentin in pain management. Anesth Analg 2000; 91: 680-7.

16 Abdi S, Lee DH, Chung JM. The anti-allodynic effects of amitriptyline, gabapentin, and lidocaine in a rat model of neuropathic pain. Anesth Analg 1998; 87: 1360-6.

17 Jun JH, Yaksh TL. The effect of intrathecal gabapentin and 3 -isobutyl $\gamma$-aminobutyric acid on the hyperalgesia observed after thermal injury in the rat. Anesth Analg 1998; 86: 348-54.

18 Field MJ, Holloman EF, McCleary S, Hughes J, Singh L. Evaluation of gabapentin and $S-(+)$-3-isobutylgaba in a rat model of postoperative pain. J Pharmacol Exp Ther 1997; 282: 1242-6.

19 Dirks J, Petersen KL, Rowbotham MC, Dabl JB.

Gabapentin suppresses cutaneous hyperalgesia following heat-capsaicin sensitization. Anesthesiology 2002; 97: 102-7.

20 Nicholson B. Gabapentin use in neuropathic pain syndromes. Acta Neurol Scand 2000; 101: 359-71.

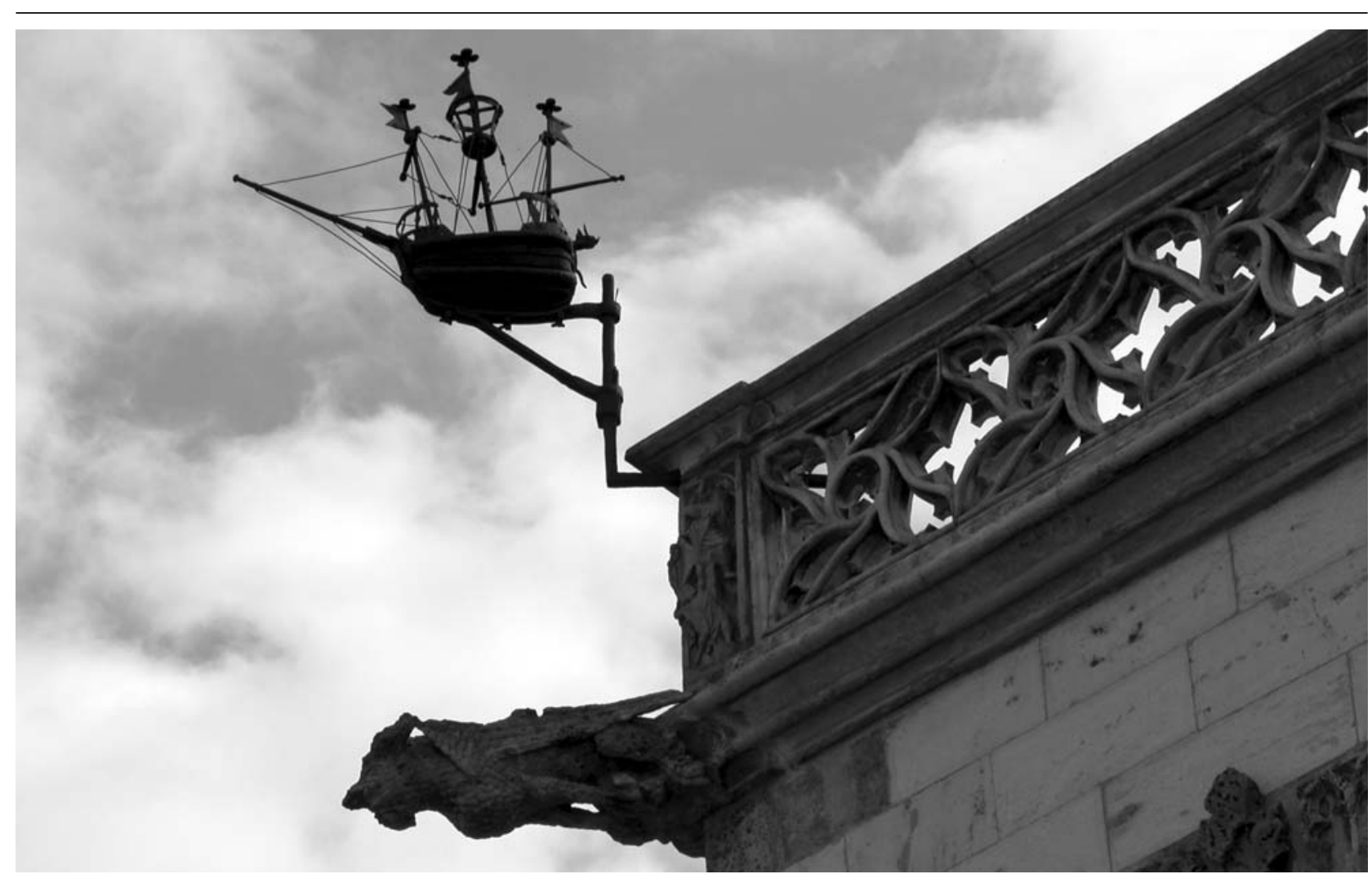

La loge de mer Perpignan 